\title{
Perspectiva Do Sacrifício No Comportamento Do Consumidor: Introduzindo Um Modelo Teórico
}

\section{Perspective Of The Sacrifice In Consumer Behavior: Introducing A Theoretical Model}

\author{
Jairo de Pontes Gomes ${ }^{1}$, Salomão Alencar de Farias ${ }^{1}$, Marianny Jessica de Brito Silva ${ }^{1}$
}

\author{
${ }^{1}$ Universidade Federal da Paraíba, UFPB, Brasil. \\ Correspondência: Jairo de Pontes Gomes. Centro de Ciências Agrárias, Campus III, Departamento de Ciências \\ Sociais Aplicadas, CCHSA/DCSA, Cidade Universitária, CEP.: 58.220-000, Bananeiras, PB, Brasil. Telefone: \\ +55 (83) 3367-1200. E-mail: jairopontes@yahoo.com.
}

Recebido: 30 de novembro de 2017 Aceito: 12 de fevereiro de 2018 Publicado: 01 de maio de 2018

DOI: http://dx.doi.org/10.21714/1679-18272017v15n2.p617-630

\begin{abstract}
Resumo
O que é sacrifício no consumo? Apesar da popularidade do termo nas retóricas dos indivíduos da sociedade contemporânea, sacrifício ainda não é bem entendido no contexto acadêmico do comportamento do consumidor. Há uma lacuna de estudos que busquem categorizar e caracterizar as práticas sacrificiais relacionadas ao consumo, trazendo elementos centrais para a construção do conceito amplo de sacrifício nas ciências. Este artigo objetiva introduzir uma interpretação, até então inédita, do sacrifício no consumo a partir das visões de diferentes áreas do conhecimento. Com a adoção de um caminho metodológico de natureza qualitativa, foram realizadas entrevistas com especialistas e revisão sistemática da literatura sobre o tema, onde a análise dos dados foi operacionalizada por meio da análise de conteúdo. Foi encontrado que o sacrifício na compra/consumo (ou não compra), envolve significações positivas e negativas, onde uma avaliação do indivíduo considera a relação custo/benefício para a realização ou não de atos que são considerados como sacrifícios.
\end{abstract}

Palavras-chave: Sacrifício. Comportamento do Consumidor. Modelo Teórico.

\begin{abstract}
What is a sacrifice in consumption? Despite the popularity of the term in the rhetoric of individuals in contemporary society, sacrifice is still not well understood in the academic context of consumer behavior. There is a gap in studies that seek to categorize and characterize sacrificial practices related to consumption, bringing the core elements to the construction of the broad concept of sacrifice in the sciences. This article aims to introduce an interpretation, hitherto unheard-of sacrifice in consumption from the views of different areas of knowledge. With the adoption of a methodological approach of a qualitative nature, interviews with specialists and a systematic review of the literature on the subject were carried out, where the data analysis was operationalized through content analysis. It was found that sacrifice in buying / consuming (or not buying) involves positive and negative significances, where an evaluation of the individual considers the cost/benefit ratio for the performance or not of acts that are considered as sacrifices.
\end{abstract}

Keywords: Sacrifice. Consumer behavior. Theoretical model.

Esta obra está licenciada sob uma Licença Creative Commons Attribution 3.0.

\section{Introdução}

O sacrifício é um construto analisado especialmente por estudiosos da religião, sociologia, filosofia e antropologia. Destaca-se, portanto, como tema complexo e multidisciplinar, estando sua linguagem presente nas atuais retóricas religiosas, políticas e da cultura popular (WATTS, 2011).

Em uma sociedade marcada por crises econômicas, sociais e de identidade, escutar a palavra sacrifício durante os diálogos do dia-a-dia não é difícil. Pessoas afirmam que realizam sacrifícios para (não) comprar, (não) usar, (não) possuir e (não) agir, realizando tal prática por causa de suas famílias, amigos, desconhecidos e por si mesmos. 
Apesar disto, há pouco consenso sobre o que é sacrifício nesta construção social atual e qual o papel do consumo neste contexto.

É inegável que a pluralidade de campos de estudo que abordam a temática em questão tem feito emergir contribuições teóricas acerca de como o sacrifício pode ser descrito, explicado e quais seus efeitos na esfera individual e coletiva (e.g. HUBERT; MAUSS, 1897; BATAILLE, 1989; SIMMEL, 2004; GIRARD, 1995; RAMP, 2008; AXINN, 2010; SHILLING; MELLOR, 2013; BUBBIO, 2013; SHIPTON, 2014). Mas, ao mesmo tempo, tal diversidade tem gerado confusões e ambiguidades apresentadas nas definições e categorizações da prática sacrificial. Por isso, qualquer transferência de sentido que possa ser feita do construto analisado para a área de Marketing deve ser antes caracterizada pelo estudo das outras ciências que já se debruçam na pesquisa do tema e pela escolha de determinadas visões de sacrifício.

Este artigo volta-se para estas lacunas ao objetivar: (1) uma discussão sobre as interpretações de sacrifício nas ciências; (2) uma construção das principais significações do construto na atualidade a partir das diferentes áreas de estudo e; (3) a definição e construção do modelo de sacrifício para o consumo.

\section{Definições e características do sacrifício}

Práticas sacrificiais são tão antigas quanto às religiões, variando de acordo com a cultura e com o contexto local. Entretanto, estudos que objetivavam identificar o caráter científico no sacrifício só começam a ser desenvolvidos a partir do século XVIII (HUBERT; MAUSS, 1897).

De acordo com James (1933), uma das principais dificuldades em compreender sacrifício é o pertencimento desta temática a diversos departamentos de pesquisa. Assim, não é possível observar uma forma única de concepção de sacrifício que trate adequadamente de todos os pontos de vista sob os quais ele pode ser considerado (EVANSPRITCHARD, 1956; BUBBIO, 2013; MATEAR, 2014; POORTHUIS; SCHWARTZ; TURNER, 2016). Por isso, algumas distinções entre as formas de estudo do construto em questão podem ser feitas. A primeira delas é voltada para pesquisas que enfatizam o sacrifício animal e, outras, que lidam com o humano. Segundo Watts (2011, p. 5), "muitos teóricos discutem os dois, mas eles inevitavelmente explicam um em termos do outro, (evidenciando) aquele que é mais central para suas teorias".

Hubert e Mauss (1897), por exemplo, desenvolvem sua pesquisa a partir da análise da tradição Védica e da tradição bíblica (hebraica) em ofertar ao Deus ou aos deuses sacrifícios com animais. Nestas culturas, os bichos eram os principais veículos de expiação e rendição de ação de graças. A oferenda ou sacrifício de animais também é apontada por Shipton (2014) como prática comum entre os povos africanos, enfatizando o comércio existente a partir do sacrifício. Animais como bois, ovelhas, galos e galinhas eram sacrificados muitas vezes de maneira arcaica a partir de regras variadas da cultura local, à exceção de anciãos e adivinhos que eram vistos como especialistas nestas práticas, sendo este sacrifício uma súplica às divindades para uma ajuda em tempos de fome, seca, doença e guerra (SHIPTON, 2014).

Para Halbertal (2012), tais rituais baseados no sacrifício de animais tinham como elemento central o desejo de adoração por um ou vários deuses. Assim, em diferentes tradições religiosas, era possível presenciar esta ação com tal motivação. Sentir maior ligação com o sagrado era o desejo observado desde os povos primitivos, que passavam a realizar os sacrifícios como traços de abnegação e renúncia (TYLOR, 1871a). Nesta perspectiva, ritos sacrificiais eram desenvolvidos com vistas a fazer do "selvagem", por meio da abnegação e renúncia, um ser consagrado à divindade de quem esperava algo em troca (TYLOR, 1871a).

Outros estudiosos buscam realçar o sacrifício humano. Bataille (1989), por exemplo, o considera um ato social fundamental, de modo que festivais de sacrifício são vistos como práticas que renovam a sociedade. Este revigorar, entretanto, só ocorre a partir de uma despesa, de um excesso de gastos (BATAILLE, 1989; RAMP, 2008). Por isso, para Bataille (1989), o sacrifício é visto como gasto, custo e despesa que, quando realizado com humanos, busca profundamente reestabelecer uma intimidade com a natureza através da renúncia (WATTS, 2011). Nesta perspectiva, observa-se o sacrifício na visão econômica de Keenan (2005) enquanto passagem necessária por meio do sofrimento.

René Girard (1995) também contribuiu para a exemplificação de sacrifício humano, realçando a característica expiatória desta prática. Nela, a violência se faz presente a partir de uma prática mimética que resulta no todos contra um, de modo que em meio a situações de tensão, enganos são praticados contra bodes expiatórios dentro e fora do grupo, culminando na expulsão violenta ou na destruição destas inocentes vidas (GIRARD, 1995). A partir deste sacrifício, a paz é reestabelecida no grupo e o bode expiatório pode ser visto como um ser sobrenatural restaurador de conflitos. Assim, o sacrifício neste aspecto é violento e destrutivo (expulsão, morte), catártico 
(purificação pela expulsão do que é estranho) e produtivo (restauração do grupo) (SHILLING; MELLOR, 2013). Outra distinção entre teorias de sacrifício é feita por Watts (2011, p. 7) a partir das fontes de informação:

Temos, por um lado, descrições de rituais sacrificiais de textos antigos (como o Levítico) e de etnógrafos modernos. Por outro lado, temos histórias - mitos, lendas e relatos historiográficos - em que os sacrifícios desempenham um papel proeminente. Embora a maioria dos teóricos invoque ambos os tipos de fontes, suas teorias do sacrifício não contam igualmente bem para ambos: algumas teorias funcionam melhor para as descrições do ritual do que para as histórias sobre sacrifícios, enquanto outras são mais aptas para histórias sobre sacrifícios do que para rituais. Além disso, esta distinção entre as teorias modernas do sacrifício é congruente com a anterior: as teorias do sacrifício que vêm as ofertas animais como primárias funcionam melhor nos textos ritualísticos, enquanto aquelas que dão primazia à morte de seres humanos se aplicam melhor às histórias.

Assim, as teorias do sacrifício vêm a tratar duas coisas diferentes; primeiramente, as que lidam com tradições narrativas sobre sacrifício humano preocupando-se com avaliações normativas deste tipo de prática e, segundo aquelas que abordam o sacrifício animal e são, assim, voltadas à função social do ritual e religião (WATTS, 2011).

Uma vez estabelecida tais distinções nos estudos de sacrifício, outras mais podem ser elencadas. Como já mencionado anteriormente, o construto em questão pode ser visto como gasto e despesa (BATAILLE, 1989) e como expiação (GIRARD, 1995). Ademais, a visão de transcendência também deve ser considerada ao lidar com aspectos sacrificiais. Simmel (2004) revela que o sacrifício envolve trocas humanas transcendentais, ao invés de meramente utilitárias, tais como trocas de tempo e de energia, podendo existir uma abnegação em prol da manutenção da alma e do espírito. Por isso, de acordo com Shiling e Mellor (2013), o ato de tornar sagrado pode envolver uma renúncia de utilidade (BATAILLE, 1989), uma entrega emocional para imitar desejos envolvendo inveja (GIRARD, 1995) e/ou um compromisso para cultivar a alma e a personalidade (SIMMEL, 2004).

De fato, o processo geral de troca tem como componente essencial o sacrifício (EVANS-PRITCHARD, 1956). Em certos ritos sacrificiais, as ideias de propiciação e expiação eram proeminentes e seu propósito era descrito por palavras com o sentido de negociação e troca.

A influência religiosa nos discursos sobre sacrifício em suas características de abnegação, expiação e transcendência revela o quão seu conceito permanece arraigado a elementos da religião. Uma distinção, porém, deve ser ressaltada. Vivencia-se uma multiplicidade de religiões e credos, cada uma com suas considerações sobre práticas sacrificiais. No catolicismo, em especial, a noção de troca, de custos e benefícios pensados para a realização do sacrifício não é adotada. A partir do sacrifício cruento de Cristo, a própria ideia de sacrifício é modificada na Igreja Católica. É o que revela Bubbio (2013) a partir das concepções de Kant sobre o sacrifício Kenótico, descrito como a aceitação do desejo divino em detrimento da vontade própria. Na visão Kenótica, não há espera de retorno pelo sacrifício. A felicidade dos outros e de Deus implica na retirada do bem-estar do que se sacrifica, sendo a felicidade dos outros o começo de tudo e o fim em si mesmo (BUBBIO, 2013).

Em geral, as formas de sacrifício não envolvem a visão Kenótica observada no catolicismo, pois frequentemente elas implicam em uma supressão e não uma retirada por completo da liberdade do sujeito, em prol da obtenção de valor não monetário (BUBBIO, 2013). Nesta perspectiva, sacrifício cria valor (AXINN, 2010) e se aproxima de uma troca, pois há a noção do dar para receber. Ou seja, há investimento, desistência, oferecimento voluntário, renúncia, gasto ou disposição de algo material ou imaterial a fim de que o doador e/ou outra pessoa possa se beneficiar com algo considerado maior, melhor e mais importante (SHIPTON, 2014).

Os sacrifícios ainda podem ser divididos em ocasionais e regulares (HUBERT; MAUSS, 1897). O primeiro diz respeito àqueles que acompanham um momento solene da vida, como nascimento e casamento; ou um rito em si, por exemplo, a coroação de um rei; já o segundo, como o próprio nome sugere, ocorre em tempos fixos, independente da vontade do ser humano e do acaso, tais como sacrifícios em festivais sazonais e as primícias no fim do ano (HUBERT; MAUSS, 1897).

No Marketing, os estudos de sacrifício surgem a partir do trabalho de Belk, Wallendorf e Sherry (1989), descrevendo-o como uma das possíveis características e manifestações do sagrado. Na pesquisa, os autores buscaram compreender os processos de (des) sacralização inerentes ao comportamento do consumidor. Em outras pesquisas na área, o sacrifício ainda é descrito como uma expressão de amor (BELK; COON, 1993; MILLER, 1998) e como o ato perfeito de presentear (SHERRY JR., 1983; BELK, 1996; BRADFORD, 2009).

De modo especial, Belk, Ger e Askergaard (2003) observam o sacrifício enquanto dimensão e processo de desejo, 
chegando até a ideia de Loureiro (2011) de que uma maior disposição para realizar um sacrifício de compra está fortemente relacionada a indivíduos com maior satisfação e comprometimento. Outros elementos considerados na perspectiva do sacrifício no consumo envolvem elementos de investimento - tais como: maior preço pago, tempo, energia, esforço, aquisição, manutenção e risco de falha (e.g. MONROE; KRISHNAN, 1985; RAVALD; GRÖNROOS, 1996; BOLTON; WARLOP; ALBA, 2003) - ou de perda (LIAO; CHEN; JHOU, 2014; MATEAR, 2014).

\section{Caminhos Metodológicos}

O construto central deste artigo indicou um caminho de pesquisa qualitativo. Buscou-se sistematizar o conhecimento na área e compreender a visão de especialistas de diferentes campos da ciência sobre o tema sacrifício. Desse modo, realizou-se inicialmente um amplo levantamento bibliográfico e em seguida foram coletados dados por meio de entrevistas pessoais, com o uso de um roteiro flexível.

O levantamento bibliográfico foi realizado com vistas a identificar estudos que definem o termo sacrifício nas diferentes perspectivas de conhecimento. Cabe destacar que nesta sondagem identificou-se uma ampla gama de estudos que contemplam o tema sacrifício, porém uma boa parte deles não define o que venha a ser esse tipo de comportamento, caracterizando-se assim, uma lacuna que este trabalho contribuirá para redução. Ao todo foram verificados 94 trabalhos, com data de publicação entre 1748 e 2016, pertencentes às distintas áreas do conhecimento (antropologia, filosofia, psicologia, economia e marketing).

Dentre os trabalhos que apresentaram uma definição do sacrifício, foram elencados, no Quadro 1, aqueles que apresentaram elementos distintos para esse construto em prol de uma definição para o sacrifício relacionado ao consumo.

\begin{tabular}{|c|c|c|c|}
\hline Área & Autor & Ano & Definição de Sacrifício \\
\hline Antropologia & Sykers & 1748 & $\begin{array}{l}\text { Qualquer coisa que é dada ou oferecida de forma solene a Deus, de } \\
\text { modo que a parte dele ou o todo seja consumido. }\end{array}$ \\
\hline Antropologia & Tylor & $1871 \mathrm{a} / \mathrm{b}$ & Uma dádiva que o selvagem entregava a seres sobrenaturais. \\
\hline Antropologia & Frazer & 1894 & $\begin{array}{l}\text { Uma forma de promoção e conservação da vida, que em alguns casos } \\
\text { implica na morte ou destruição da pessoa ou objeto ofertado. }\end{array}$ \\
\hline Antropologia & $\begin{array}{l}\text { Hubert e } \\
\text { Mauss }\end{array}$ & 1897 & $\begin{array}{l}\text { Ato religioso que, mediante a consagração de uma vítima, modifica o } \\
\text { estado da pessoa moral que o efetua ou de certos objetos pelos quais ela } \\
\text { se interessa. }\end{array}$ \\
\hline Psicanálise & Freud & 1913 & Uma forma de renúncia de algo que tem valor para o indivíduo. \\
\hline Antropologia & $\begin{array}{l}\text { Evans- } \\
\text { Pritchard }\end{array}$ & 1956 & $\begin{array}{l}\text { Uma forma de fazer negócios entre os deuses e os homens, uma } \\
\text { negociação na qual uma troca era realizada. }\end{array}$ \\
\hline Psicanálise & Lacan & 1962 & A captura do Outro como tal na rede do desejo. \\
\hline Antropologia & Firth & 1963 & $\begin{array}{l}\text { O sacrifício é desistir de algo a um custo. É a perda provocada pela } \\
\text { devoção a algum outro interesse. }\end{array}$ \\
\hline Economia & Bataille & 1989 & $\begin{array}{l}\text { Restitui ao mundo sagrado o que o uso servil degradou, tornou profano. } \\
\text { Nesta perspectiva, sacrificar envolve uma renúncia de utilidade, um } \\
\text { custo que revigora a sociedade. }\end{array}$ \\
\hline Marketing & Monroe & 1991 & $\begin{array}{l}\text { Sacrifício percebido inclui todos os custos que o comprador enfrenta ao } \\
\text { fazer uma compra, tais como: preço de compra, custos de aquisição, } \\
\text { transporte, instalação, manuseio, reparos e manutenção, risco de falha } \\
\text { ou mau desempenho. }\end{array}$ \\
\hline Antropologia & Girard & 1995 & $\begin{array}{l}\text { Sacrifício é um mecanismo que catalisa práticas violentas dirigidas } \\
\text { contra uma única vítima, sendo esta pessoa um bode expiatório que tem } \\
\text { como função catalisar a violência dos demais membros do grupo, de } \\
\text { modo a evitar que ela alcance a comunidade como um todo. }\end{array}$ \\
\hline
\end{tabular}




\begin{tabular}{|c|c|c|c|c|}
\hline Marketing & $\begin{array}{c}\text { Ravald e } \\
\text { Grönroos }\end{array}$ & 1996 & Preço que um indivíduo está disposto a pagar para aquisição de um bem \\
ou serviço.
\end{tabular}

Quadro 1: Levantamento Bibliográfico sobre definição do sacrifício.

Fonte: Elaboração própria (2017).

De maneira geral, a partir das definições de sacrifício encontradas e expostas no Quadro 1, três conjuntos de elementos, que trazem entre si o significado do construto analisado, podem ser identificados. Eles são: troca, custo e benefício (Figura 1).

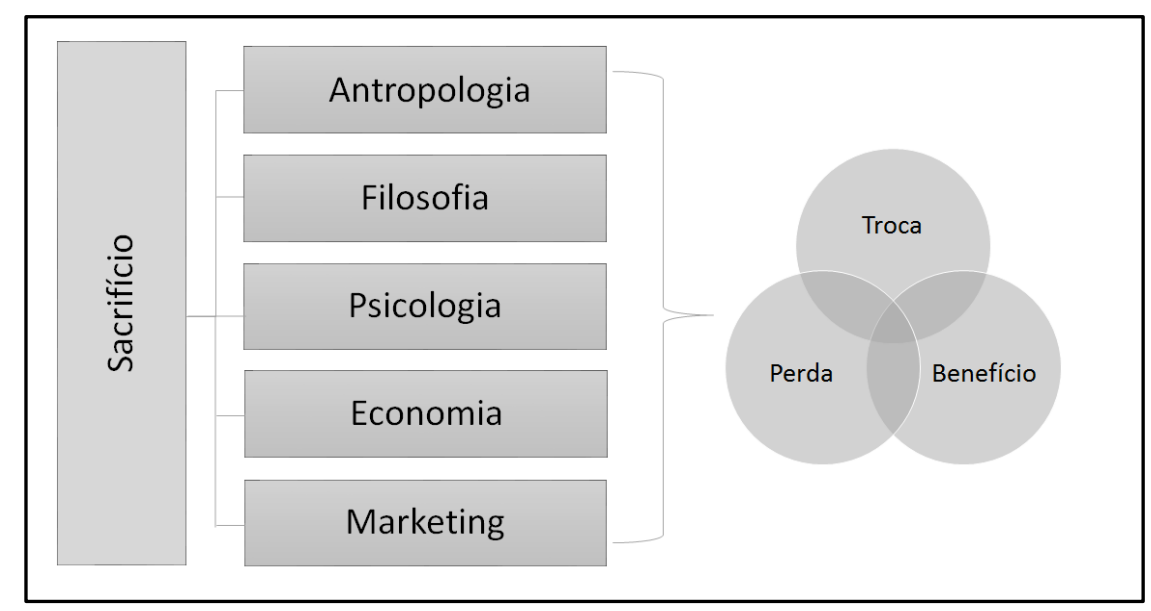

Figura 1: Elementos comuns na definição de sacrifício

Fonte: Elaboração própria (2017).

Com isso, é possível entender e conceituar o sacrifício, no contexto do consumo, como um processo de troca no qual o indivíduo opta por renunciar a algo que valoriza (monetário ou não) visando obter algum benefício de maior importância. Tal definição dá base para a construção do Modelo hipotético do processo de sacrifício para o consumo desenvolvido ao longo deste artigo.

Ademais, para a coleta de dados, com o objetivo de se obter uma melhor visão das diferentes perspectivas do 
sacrifício, definiu-se como sujeitos de pesquisa professores (mestres e doutores), com destaque em suas respectivas áreas de conhecimento e que tivessem afinidade com o tema pesquisado. O número de entrevistas foi definido pelo critério de saturação teórica. Esse critério se caracteriza pela suspensão da realização de novas entrevistas quando os dados obtidos passam a não apresentar novos conhecimentos ou perspectivas (DENZIN; LINCOLN, 2005; FLICK, 2008). Para Eisenhardt (1989) em algum momento a saturação ocorrerá nas proposições emergentes, de modo que é improvável que uma nova interação proporcione aprendizado incremental significativo. Dessa forma, as entrevistas foram suspensas no $17^{\circ}$ entrevistado, por considera-se ter-se atingindo a saturação teórica. $\mathrm{O}$ Quadro 2 apresenta o perfil dos dezessete informantes.

\begin{tabular}{|l|l|l|l|}
\hline Informante & \multicolumn{1}{|c|}{ Área } & Titulação & \multicolumn{1}{|c|}{ Profissão } \\
\hline 1 & Teologia & Mestrado & Professor e Padre \\
\hline 2 & Psicologia & Doutorado & Professora \\
\hline 3 & Sociologia e Psicologia (Psicanálise) & Doutorado & Professor \\
\hline 4 & Filosofia & Doutorado & Professor \\
\hline 5 & Antropologia & Doutorado & Professor \\
\hline 6 & Finanças & Doutorado & Professor \\
\hline 7 & Marketing e Filosofia & Doutorado & Professor \\
\hline 8 & Administração & Doutorado & Professor \\
\hline 9 & Sociologia & Doutorado & Professora \\
\hline 10 & Serviço Social & Doutorado & Professora \\
\hline 11 & Economia & Doutorado & Professor \\
\hline 12 & Administração & Mestrado & Professor \\
\hline 13 & Serviço Social & Mestrado & Professora \\
\hline 14 & Economia & Doutorado & Professora \\
\hline 15 & Engenharia Mecânica & Doutorado & Professor \\
\hline 16 & Física & Doutorado & Professor \\
\hline 17 & Administração & Doutorado & Professor \\
\hline
\end{tabular}

Quadro 2: Perfil dos informantes.

Fonte: Elaboração própria (2017).

As entrevistas foram realizadas nos meses de outubro e novembro de 2016 seguindo um roteiro inicial de questões que foi elaborado para desencadear novos questionamentos influenciados pelas respostas iniciais dos entrevistados.

Todas as entrevistas foram gravadas, com anuência dos informantes, e complementadas com notas de campo. O tempo médio de gravação foi de 12 minutos, descontada a fase inicial de apresentação. Após a coleta, os dados foram transcritos por pessoa externa e revisados pelos pesquisadores. A análise e interpretação dos dados coletados foram operacionalizadas por meio da análise de conteúdo, que se caracteriza como:

Um conjunto de técnicas de análise das comunicações visando obter por procedimentos sistemáticos e objetivos de descrição do conteúdo das mensagens indicadores (quantitativos ou não) que permitam a inferência de conhecimentos relativos às condições de produção/recepção (variáveis inferidas) destas mensagens (BARDIN, 2011, p. 48).

A análise de conteúdo revela-se importante para se obter novos insights, aumentar a compreensão do pesquisador sobre fenômenos particulares ou informar ações práticas (KRIPPENDORFF, 2012). Sua execução envolve algumas etapas que visam proporcionar significado aos dados coletados (NEUENDORF, 2002), no entanto, existe uma diferenciação no uso das terminologias para cada uma das etapas expostas por distintos autores (e.g. BARDIN, 2011; KRIPPENDORFF, 2012). Optou-se por empregar como norteador do presente trabalho as etapas expostas por Bardin (2011), tendo em vista a ampla utilização e popularidade nas pesquisas em administração. A proposta 
de Bardin (2011) contempla três fases: pré-análise, exploração do material e o tratamento dos resultados, a inferência e a interpretação.

A fase de pré-análise se concretizou pela leitura das transcrições das entrevistas e das notas de campo, além da audição das gravações realizadas. A composição do corpus de análise levou em consideração as regras de representatividade, exaustividade, homogeneidade e pertinência, sendo consideradas todas as entrevistas pertinentes a serem submetidas aos procedimentos analíticos.

A segunda fase, exploração do material, em termos gerais consistiu em operações de codificação, decomposição ou enumeração, em função de regras previamente formuladas (BARDIN, 2011). A codificação é descrita como a transformação realizada por meio de regras precisas e caracteriza-se como o recorte, agregação e enumeração dos dados brutos do texto permitindo obter uma representação do conteúdo ou de sua expressão. Nesta fase da presente investigação, o texto das entrevistas foi recortado em unidades de registro. Tomou-se como unidades de registro os parágrafos de cada entrevista e as anotações do diário de campo. Em seguida, foram identificadas em cada parágrafo, termos-chave e feito um resumo visando operacionalizar a primeira categorização. É importante destacar que, mesmo tendo sido realizado previamente um levantamento bibliográfico, no qual identificou-se algumas categorias do sacrifício, nesta etapa, deixou-se emergir as categorias a partir das falas dos sujeitos. Em seguida as categorias iniciais foram agrupadas tematicamente, procedimento que originou as categorias intermediárias e por fim, as categorias intermediárias foram reunidas em função das consequências do ato de sacrifício. Dessa forma, obteve-se a definição das categorias finais.

A terceira fase, tratamento dos resultados, inferência e interpretação, consiste em captar os conteúdos do material coletado (dados brutos das entrevistas, documentos e observações) e tratá-los de maneira a serem significativos e válidos (BARDIN, 2011). No presente estudo, as inferências e interpretações foram desenvolvidas tendo como base o levantamento da literatura sobre sacrifício.

\section{Percepções de Sacrifício: Análise Exploratória}

Visando-se atender ao caráter exploratório desta etapa da pesquisa, cujo objetivo principal é obter maior compreensão do sacrifício nas diferentes perspectivas do conhecimento, analisaram-se as entrevistas realizadas com especialistas por meio da técnica de análise categorial. De acordo com Bardin $(2011$, p. 201) a análise por categorias consiste em "operações de desmembramento do texto em unidades, em categorias segundo reagrupamentos analógicos". Esse tipo de análise torna-se relevante quando se busca estudar valores, opiniões, atitudes e crenças. (SILVA, 2012).

A configuração das categorias iniciais se deu como resultado das primeiras impressões da percepção de sacrifício apresentadas pelos entrevistados. Desta fase, emergiram dezoito categorias iniciais, concebidas e nomeadas a partir de trechos selecionados das falas dos entrevistados. O Quadro 3 descreve as categorias iniciais e o conceito norteador de cada uma delas.

\begin{tabular}{|l|l|}
\hline \multicolumn{1}{|c|}{ Exemplo de trechos selecionados das falas dos entrevistados } & \multicolumn{1}{|c|}{$\begin{array}{c}\text { Categoria } \\
\text { Inicial }\end{array}$} \\
\hline $\begin{array}{l}\text { Sacrifícios só com muito amor, à profissão, ao ser humano, a filho e uma série de coisas } \\
\text { (Entrevistado 10). }\end{array}$ & 1. Amor \\
\hline $\begin{array}{l}\text { Você faz muito sacrifício para chegar numa zona de conforto, isso levou a uma necessidade } \\
\text { de um esforço extra. Por acreditar naquilo você enfrentou isso e gerou um efeito de liberdade, } \\
\text { de domínio de uma situação. Esforço extra, essa renúncia de outras coisas, de outros prazeres. } \\
\text { Viver essa experiência elas precisam acreditar, elas precisam desejar, querer. Em busca de } \\
\text { uma meta em busca de um objetivo maior (Entrevistado 12). }\end{array}$ & 2. Crença \\
\hline $\begin{array}{l}\text { Um serviço ao extremo, isso é um sacrifício. O serviço que pode ser ao próximo, um serviço } \\
\text { que pode ser aquele que precisa. Sacrifício tem a ver com alguém que é capaz de oferecer } \\
\text { algo a mais, um serviço ao outro (Entrevistado 12). }\end{array}$ & 3. Dedicação \\
\hline Sacrifício, eu acho que seria impossibilidade ou dificuldade (Entrevistado 13). & 4. Dificuldade \\
\hline Sacrifício é fazer alguma coisa em detrimento a outra. Troca né, escolha (Entrevistado 6). & 5. Escolha \\
\hline Sacrifício é fazer algo além de suas condições provisórias (Entrevistado 8). & 6. Esforço \\
\hline $\begin{array}{l}\text { Sacrifício é fazer alguma coisa que dá muito trabalho, requer um esforço extra (Entrevistado } \\
\text { 4). }\end{array}$ & \\
\hline
\end{tabular}




\begin{tabular}{|c|c|}
\hline $\begin{array}{l}\text { Olah (holocausto) é a verdadeira palavra para a ideia de sacrifício, uma palavra em hebraico } \\
\text { (Entrevistado 5). }\end{array}$ & 7. Holocausto \\
\hline Perder um conforto para adquirir um bem. Um investimento. (Entrevistado 2) & \multirow[b]{2}{*}{ 8. Investimento } \\
\hline $\begin{array}{l}\text { Sacrifício entra na vida da gente de uma forma ritualística, você faz uma coisa esperando } \\
\text { outra (Entrevistado 7) }\end{array}$ & \\
\hline $\begin{array}{l}\text { As pessoas não fazem sacrifícios, elas maximizam o seu bem-estar fazendo escolhas. O } \\
\text { sacrifício é apenas uma consequência. (Entrevistado 14). }\end{array}$ & $\begin{array}{l}\text { 9. Maximizar o } \\
\text { bem-estar }\end{array}$ \\
\hline $\begin{array}{l}\text { A própria necessidade da sociedade que está gerando uma restrição e você está sendo levado } \\
\text { ao sacrifício (Entrevistado 11). }\end{array}$ & $\begin{array}{l}10 . \\
\text { Necessidade }\end{array}$ \\
\hline (...) sacrifício para alcançar um ideal, um ideal nosso, né! (Entrevistado 13). & 11. Ideal \\
\hline $\begin{array}{l}\text { Sacrifício é uma atividade que traz dor ou desprazer, é uma coisa que a gente faz com muito } \\
\text { peso, muito penoso, um coisa ruim (Entrevistado 2). }\end{array}$ & 12. Sofrimento \\
\hline $\begin{array}{l}\text { Quando você faz o sacrifício ou renúncia alguma coisa, você perde. Pode perder } \\
\text { materialmente, e pode perder emocionalmente (Entrevistado 11) }\end{array}$ & $\begin{array}{l}\text { 13. Sentimento } \\
\text { de perda }\end{array}$ \\
\hline Quando você assume risco você também está se sacrificando (Entrevistado 17) & 14. Risco \\
\hline $\begin{array}{l}\text { Se mudar o sacrifício para sofrimento, a pessoa tem que matar uma parte dela que ela não } \\
\text { consegue lhe dar, para no lugar, ela construir uma outra parte, onde ela possa ter algum tipo } \\
\text { de prazer ou de uma situação afável consigo próprio (Entrevistado } 3 \text { ). }\end{array}$ & 15. Prazer \\
\hline As pessoas realizam o sacrifício na busca por realização (Entrevistado 8). & \multirow{2}{*}{ 16. Realização } \\
\hline O sacrifício nesse sentido é um elemento de realização, não de punição (Entrevistado 1) & \\
\hline $\begin{array}{l}\text { Renúncia de algo que, até então tinha como apropriado para si e em prol desse algo que eu } \\
\text { acredito, me submeto aquele sacrifício. (Entrevistado 12). }\end{array}$ & \multirow{3}{*}{ 17. Renúncia } \\
\hline $\begin{array}{l}\text { Sacrifício seria algo que envolve a negação temporária ou permanente de alguma necessidade } \\
\text { ou de algum prazer ou de algum desejo (Entrevistado 9). }\end{array}$ & \\
\hline $\begin{array}{l}\text { Alguma possibilidade de eu fazer alguma coisa em prol de fazer outra. Está relacionado com } \\
\text { o fato de eu não conseguir escolher uma coisa em detrimento de outra, ao escolher uma coisa } \\
\text { eu renegue o direito a possibilidade que eu tenho de escolher no futuro (Entrevistado 16). }\end{array}$ & \\
\hline $\begin{array}{l}\text { Sacrifício como um caminho de redenção, que leva a pessoa - ser humano - a superar a si } \\
\text { próprio, a superar as suas fraquezas mediante uma prática penitencial [...]. Não é vivenciar } \\
\text { apenas a experiência de dor pela dor, mas é uma meta, um caminho de redenção (Entrevistado } \\
\text { 1). }\end{array}$ & \multirow{2}{*}{ 18. Superação } \\
\hline $\begin{array}{l}\text { Basicamente é superar os medos, superar as limitações, superar crenças até, é basicamente } \\
\text { isso, superar suas limitações [...]. Sacrifício é você ceder as suas limitaçôes, é você atuar de } \\
\text { forma, ultrapassando todos os limites da sua capacidade, seja ela intelectual, seja ela física, } \\
\text { seja ela financeira (Entrevistado 15). }\end{array}$ & \\
\hline
\end{tabular}

Quadro 3: Categorias iniciais da Análise de Conteúdo.

Fonte: Elaboração própria (2017).

Buscando o aprimoramento da análise dos dados, realizou-se o agrupamento progressivo das categorias iniciais que resultaram na emergência de sete categorias intermediárias. Este procedimento tomou como base as falas dos entrevistados e no referencial teórico. $\mathrm{O}$ agrupamento das primeiras três categorias resultou na primeira categoria intermediária denominada Sentimento de adoração, conforme demonstrado no Quadro 4.

\begin{tabular}{|l|l|c|}
\hline \multicolumn{1}{|c|}{$\begin{array}{c}\text { Categoria } \\
\text { Inicial }\end{array}$} & \multicolumn{1}{|c|}{ Conceito norteador } & \multicolumn{1}{c|}{$\begin{array}{c}\text { Categoria } \\
\text { Intermediária }\end{array}$} \\
\hline 1. Amor & $\begin{array}{l}\text { Caracteriza-se pelo sentimento de adoração em relação a algo } \\
\text { específico }\end{array}$ & $\begin{array}{l}\text { I. Sentimento de } \\
\text { adoração }\end{array}$ \\
\hline 2. Crença & Exprime o processo mental ou atitude de quem acredita em algo.
\end{tabular}




\begin{tabular}{|l|l|l|}
\hline 3. Dedicação & Referência o devotamento, a uma causa ou pessoa & \\
\hline
\end{tabular}

Quadro 4: Categoria Intermediária I: Sentimento de adoração.

Fonte: Elaboração própria (2017).

A Categoria Intermediária "Sentimento de adoração" refere-se ao carinho, afeto, veneração ou amor exagerado a um objeto ou alguém. O sentimento de adoração está associado ao sacrifício desde os primeiros estudos antropológicos. Tylor (1871a, 1871b) ao descrever os rituais de sacrifício, destaca no animismo a associação entre a adoração de ídolos e práticas de sacrifício. Na mesma perspectiva, Halbertal (2012) expõe que os rituais de sacrifício de animais, em diferentes tradições religiosas, tinham como principal motivação a adoração.

A segunda categoria intermediária, denominada "Ato Penoso", deu-se a partir da junção das categorias iniciais: Dificuldade, Esforço, Holocausto e Sofrimento, e representa dor, sofrimento ou desconforto proveniente do sacrifício (Quadro 5). Os aspectos negativos do sacrifício refletidos nesta categoria foram abordados por diversas perspectivas do conhecimento. Por exemplo, expondo uma visão econômica do sacrifício, Keenan (2005, p. 10) destaca que o sacrifício é "uma passagem necessária através do sofrimento (...)". Na visão sociológica, Bataille (1989) demonstra o sacrifício enquanto renovação que só pode ocorrer a partir de despesas, gastos e custos.

\begin{tabular}{|l|l|l|}
\hline \multicolumn{1}{|c|}{$\begin{array}{c}\text { Categoria } \\
\text { Inicial }\end{array}$} & \multicolumn{1}{|c|}{ Conceito norteador } & \multicolumn{1}{c|}{$\begin{array}{c}\text { Categoria } \\
\text { Intermediária }\end{array}$} \\
\hline 4. Dificuldade & Caracteriza atividade custosa, árdua & \multirow{2}{*}{ II. Ato penoso } \\
\hline 6. Esforço & $\begin{array}{l}\text { Revela a intensificação das forças físicas, intelectuais ou morais } \\
\text { para a realização do sacrifício }\end{array}$ & \multicolumn{1}{|c|}{} \\
\cline { 1 - 2 } 7. Holocausto & Denota a destruição de algo & $\begin{array}{l}\text { Evidência sentimento negativo proveniente de dor moral, física ou } \\
\text { dificuldade financeira. }\end{array}$ \\
\cline { 1 - 2 } 12. Sofrimento &
\end{tabular}

Quadro 5: Categoria Intermediária II: Ato Penoso.

Fonte: Elaboração própria (2017).

A terceira categoria intermediária, intitulada de "Troca", emergiu do agrupamento das categorias iniciais: Escolha, Ideal e Renúncia, conforme desenvolvido no Quadro 6. Esta categoria evidencia o sacrifício como um processo de troca no qual o indivíduo tem opção de escolha. A perspectiva de troca no sacrifício foi ressaltada por de EvansPritchard (1956), que considerou o sacrifício como componente essencial no processo geral de troca. Para este autor, em determinados ritos de sacrifícios, as ideias de propiciação e expiação (Girard, 1995) eram proeminentes e seu propósito era descrito por palavras com o sentido de negociação e troca. Esta troca não se restringe ao aspecto utilitário, mas também transcendental, como revelado por Simmel (2004).

\begin{tabular}{|l|l|l|}
\hline \multicolumn{1}{|c|}{$\begin{array}{c}\text { Categoria } \\
\text { Inicial }\end{array}$} & \multicolumn{1}{|c|}{ Conceito norteador } & \multicolumn{1}{c|}{$\begin{array}{c}\text { Categoria } \\
\text { Intermediária }\end{array}$} \\
\hline 5. Escolha & $\begin{array}{l}\text { Denota a preferência que se dá a alguma coisa que se encontra } \\
\text { entre outras. }\end{array}$ & \multirow{2}{*}{ III. Troca } \\
\cline { 1 - 2 } 11. Ideal & $\begin{array}{l}\text { Indica algo que se pretende alcançar, realizar ou obter quando se } \\
\text { realiza um sacrifício. }\end{array}$ & \multicolumn{1}{|c|}{} \\
\cline { 1 - 2 } 17. Renúncia & Salienta abrir mão de que algo satisfaz em prol de algo ou alguém & \\
\hline
\end{tabular}

Quadro 6: Categoria Intermediária III: Troca.

Fonte: Elaboração própria (2017).

As próximas duas categorias intermediárias não representam agrupamentos das categorias iniciais, uma vez que apresentam elementos distintos ou que revelam elementos importantes na caracterização do sacrifício. Por este motivo, decidiu-se manter a nomenclatura das categorias iniciais. Assim, a categoria intermediária IV continuou intitulada de "Necessidade" e representa o sentimento que leva uma pessoa a fazer alguma coisa. O pensamento de que a necessidade é um componente do sacrifício, foi destacada nos primeiros estudos científicos do sacrifício. De acordo com Tylor (1871a) os povos primitivos motivados pela necessidade de maior ligação com os deuses desenvolveram seus rituais sacrificiais com características de abnegação e renúncia.

A categoria intermediária V, nomeada de "Investimento", caracteriza a aplicação de recursos (dinheiro, tempo, energia, material, etc.) visando obter um benefício. Essa visão é apresentada na literatura do sacrifício contemporânea, principalmente nas perspectivas da psicologia e do marketing. Nos relacionamentos, o sacrifício 
é utilizado para descrever doação de tempo, energia e recursos, a exemplo do cuidado dos pais com um filho (e.g. BAHR; BAHR, 2001; IMPETT; GORDON, 2008; OWEN; FINCHAM; POLSER, 2016). No caso do consumo, a abordagem do sacrifício é apontada principalmente como investimento.

A próxima categoria intermediária, chamada de "Satisfação", é proveniente da junção das categorias iniciais: Maximizar o bem-estar; Prazer; Superação e Realização (Quadro 7). Esta categoria representa o prazer resultante da realização daquilo que se espera ou se deseja. A satisfação é retratada na literatura do sacrifício, a partir de estudos que descrevem a associação entre a disposição para realização do sacrifício e o alto grau de satisfação nos relacionamentos (LOUREIRO, 2011).

\begin{tabular}{|l|l|l|}
\hline \multicolumn{1}{|c|}{$\begin{array}{c}\text { Categoria } \\
\text { Inicial }\end{array}$} & \multicolumn{1}{|c|}{ Conceito norteador } & \multicolumn{1}{|c|}{$\begin{array}{c}\text { Categoria } \\
\text { Intermediária }\end{array}$} \\
\hline $\begin{array}{l}\text { 9. Maximizar o } \\
\text { bem-estar }\end{array}$ & Caracteriza-se pela busca da satisfação física e mental & \\
\hline 15. Prazer & $\begin{array}{l}\text { Indica a sensação agradável de contentamento ou de alegria, } \\
\text { normalmente relacionada à satisfação de um desejo, vontade ou } \\
\text { necessidade }\end{array}$ & \multirow{2}{*}{ VI. Satisfação } \\
\cline { 1 - 2 } 16. Realização & $\begin{array}{l}\text { Caracteriza-se pela satisfação proveniente do cumprimento de uma } \\
\text { meta ou objetivo. }\end{array}$ & \\
\cline { 1 - 2 } 18. Superação & $\begin{array}{l}\text { É caracterizada pela satisfação de vencer obstáculos e dificuldades, } \\
\text { representando uma melhoria na vida do indivíduo. }\end{array}$ & \\
\hline
\end{tabular}

Quadro 7: Categoria Intermediária VI: Satisfação.

Fonte: Elaboração própria (2017).

Por fim, a última categoria intermediária, descrita como "Custo", foi composta pela fusão das categorias iniciais: Perda material e emocional e Risco. Tal composição visa expressar a perda associada ao ato de sacrifício. Essa visão é exposta na literatura de Marketing ao descrever a percepção do sacrifício realizado pelo consumidor como um processo avaliativo de potenciais perdas, monetárias e não monetárias (e.g. LIAO; CHEN; JHOU, 2014; MATEAR, 2014). Esta categoria é exposta no Quadro 8.

\begin{tabular}{|l|l|l|}
\hline Categoria Inicial & \multicolumn{1}{|c|}{ Conceito norteador } & \multicolumn{1}{|c|}{$\begin{array}{c}\text { Categoria } \\
\text { Intermediária }\end{array}$} \\
\hline $\begin{array}{l}\text { 13. Sentimento de } \\
\text { perda }\end{array}$ & $\begin{array}{l}\text { Expõe o sentimento de ausência ou processo de deixar de } \\
\text { possuir algo em virtude do sacrifício }\end{array}$ & VII. Custo \\
\hline 14. Risco & $\begin{array}{l}\text { Expressa a possibilidade de não se obter benefício com } \\
\text { realização do sacrifício }\end{array}$ & \\
\hline
\end{tabular}

Quadro 8: Categoria Intermediária VII: Custo.

Fonte: Elaboração própria (2017).

As categorias iniciais e intermediárias expostas anteriormente deram suporte para concepção de duas categorias finais, denominadas de "Benefício emocional e/ou material" e "Perda material e emocional", conforme apresentado no Quadro 9.

\begin{tabular}{|c|c|c|c|}
\hline Categoria Inicial & $\begin{array}{c}\text { Categoria } \\
\text { Intermediária }\end{array}$ & Conceito Norteador & Categoria Final \\
\hline 1. Amor & \multirow{3}{*}{$\begin{array}{l}\text { I. Sentimento de } \\
\text { adoração }\end{array}$} & \multirow{3}{*}{$\begin{array}{l}\text { Algo ou alguém que é alvo de carinho, } \\
\text { afeto, veneração ou amor exagerado }\end{array}$} & \multirow{7}{*}{$\begin{array}{l}\text { A) Benefício } \\
\text { emocional e/ou } \\
\text { material }\end{array}$} \\
\hline 2. Crença & & & \\
\hline 3. Dedicação & & & \\
\hline 5. Escolha & \multirow{3}{*}{ III. Troca } & \multirow{3}{*}{$\begin{array}{l}\text { Indica o sacrifício como um processo de } \\
\text { troca no qual o indivíduo tem opção de } \\
\text { escolha }\end{array}$} & \\
\hline 11. Ideal & & & \\
\hline 17. Renúncia & & & \\
\hline 10. Necessidade & IV. Necessidade & Sentimento que leva uma pessoa a fazer & \\
\hline
\end{tabular}




\begin{tabular}{|c|c|c|c|}
\hline & & alguma coisa & \\
\hline 8. Investimento & V. Investimento & $\begin{array}{l}\text { Aplicação de recurso (dinheiro, tempo, } \\
\text { energia, material, etc.) visando obter um } \\
\text { ganho }\end{array}$ & \\
\hline $\begin{array}{l}\text { 9. Maximizar o } \\
\text { bem-estar }\end{array}$ & \multirow{4}{*}{ VI. Satisfação } & \multirow{4}{*}{$\begin{array}{l}\text { Prazer resultante da realização daquilo } \\
\text { que se espera ou se deseja }\end{array}$} & \\
\hline 15. Prazer & & & \\
\hline 16. Realização & & & \\
\hline 18. Superação & & & \\
\hline 4. Dificuldade & \multirow{4}{*}{ II. Ato penoso } & \multirow{4}{*}{$\begin{array}{l}\text { Ato que causa dor, sofrimento ou } \\
\text { desconforto }\end{array}$} & \multirow{6}{*}{$\begin{array}{l}\text { B) Perda material } \\
\text { e/ou emocional }\end{array}$} \\
\hline 6. Esforço & & & \\
\hline 7. Holocausto & & & \\
\hline 12. Sofrimento & & & \\
\hline $\begin{array}{l}\text { 13. Sentimento de } \\
\text { Perda }\end{array}$ & \multirow{2}{*}{ VII. Custo } & \multirow{2}{*}{ Perda associada ao ato de sacrifício } & \\
\hline 14. Risco & & & \\
\hline
\end{tabular}

Quadro 9: Categorias Finais.

Fonte: Elaboração própria (2017).

A categoria final "Benefício emocional e/ou material" foi concebida a partir do agrupamento das categorias intermediárias: Sentimento de adoração; Troca; Necessidade; Investimento e Satisfação. Esta categoria exprime a motivação subjacente para realização do ato de sacrifício e encontra-se respaldada pelas primeiras abordagens do sacrifício. De acordo (TYLOR, 1871a), o sacrifício inicialmente era uma dádiva que o selvagem entregava a seres sobrenaturais para assegurar seu favor ou minimizar sua hostilidade. Ou seja, a motivação para realização do ato tinha como aspecto latente a busca por um benefício. Na Perspectiva do marketing, a visão que associa o sacrifício ao ato de presentear o descreve como um processo relacionado a um interesse pessoal ou troca recíproca (SHERRY JR., 1983; BELK, 1996; BRADFORD, 2009). Por esse entendimento, o sacrifício é gerado para se obter algo, seja de fortalecimento das relações sociais ou como um investimento na busca de um retorno futuro.

A segunda categoria final "Perda material e/ou emocional", foi composta a partir das categorias intermediárias "Ato penoso" e "Custo". Sua concepção descreve os aspectos negativos gerados pelo sacrifício. Essa vertente tem sido uma das abordagens mais comuns nas distintas perspectivas de sacrifícios. $\mathrm{Na}$ Visão antropológica, a teoria da abnegação (abnegation theory) concebida por Tylor (1871a), descreve o surgimento de ritos sacrificiais com características de abnegação e renúncia. Ou seja, a realização do sacrifício trazia consigo uma perda associada a partir de atos de abnegação e renúncia.

$\mathrm{Na}$ ótica econômica, a consequência negativa do sacrifício pode ser percebida no exposto por Simmel (2004) ao associar as trocas econômicas com sacrifício e descrever esse processo como um ato que sempre existirá a perda de um bem útil. Na concepção do Marketing, em uma definição mais recente do sacrifício, Matear (2014) expõe que $o$ ato de sacrifício gera sensação de perda pessoal significativa.

Assim, diante do exposto, verifica-se que as duas categorias finais, geradas a partir de um processo de análise que tomou como base a fala dos entrevistados, encontra respaldo na literatura possibilitando propor inferências e interpretações acerca do sacrifício para o consumo, conforme exposto a seguir.

\section{Modelo hipotético do processo de sacrifício para o consumo}

O processo de Análise de Conteúdo possibilitou o tratamento de dados brutos de maneira a torná-los significativos e válidos. Os resultados enriquecidos com a confrontação teórica possibilitaram inferências que serviram de base para concepção de um modelo hipotético do processo de sacrifício para o consumo (Figura 2).

De forma geral, o modelo concebido na Figura 2 inicia-se com a existência de uma oferta de mercado (I), que está associada a uma necessidade do consumidor (II), influenciada, pelo sentimento de adoração (amor, crença e importância). A necessidade ao encontrar a oferta poderá formar um objetivo (III) que, por sua vez, leva o indivíduo a um processo de comparação (IV) entre a perda emocional e/ou material que terá (B) e o benefício que irá obter 
(A).

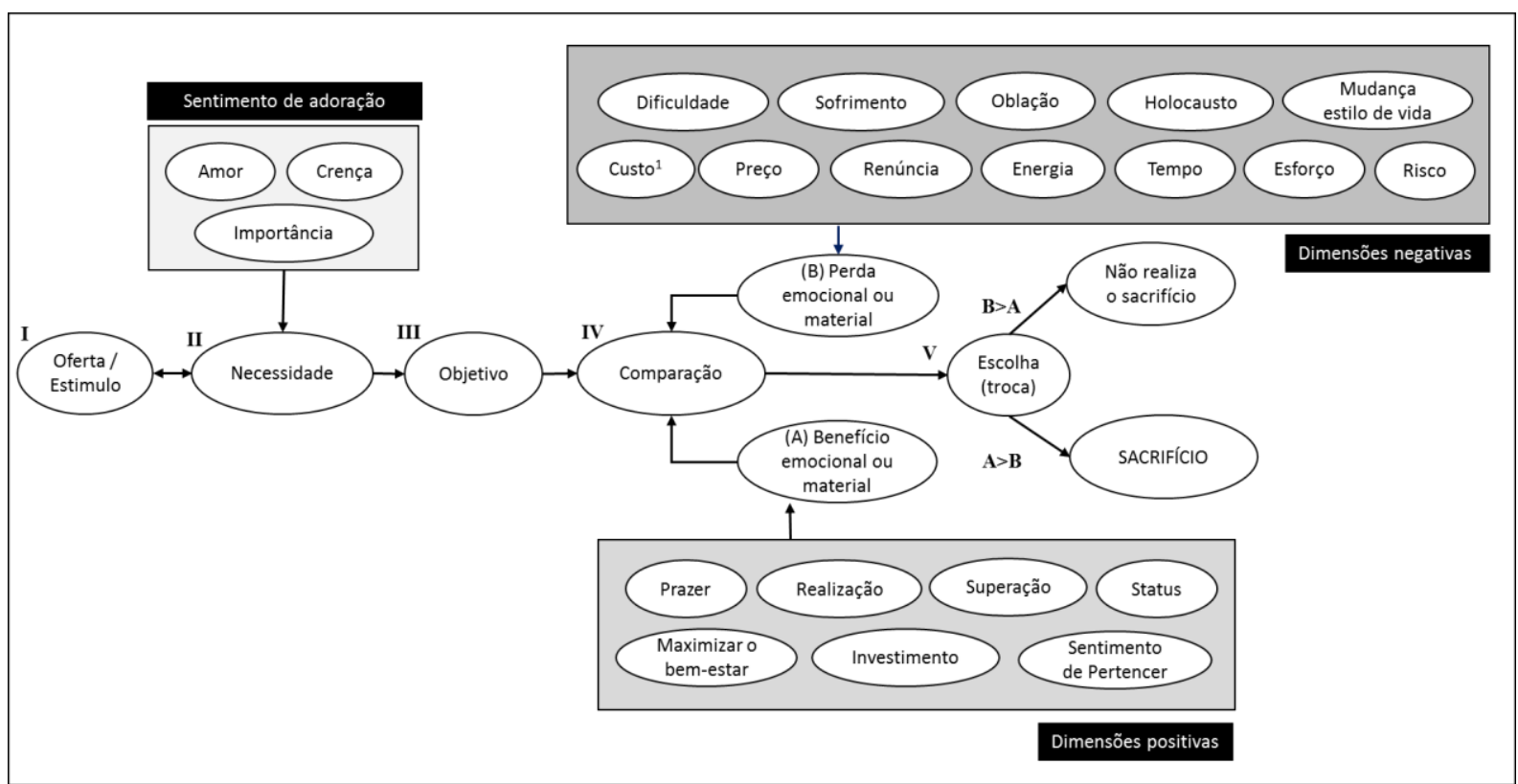

Figura 2: Modelo hipotético do processo de sacrifício para o consumo.

Fonte: Elaboração própria (2017).

A partir desse processo comparativo, o indivíduo estará apto a escolher (V) entre as duas alternativas: propensão a realizar o sacrifício, caso a relação se apresente com $\mathrm{A}>\mathrm{B}$ ou tenderá a não realizar o sacrifício caso a relação seja $\mathrm{B}>\mathrm{A}$.

Certamente, como um modelo, estamos simplificando a realidade. Em um contexto mais amplo, o ato do sacrifício relacionado a rituais de compra e/ou consumo, tento foco em objetos sagrados e profanos, pode acontecer de uma maneira mais complexa do que o modelo aqui apresentado. No entanto, a contribuição aqui apresentada reside em dois pontos centrais, a sistematização do construto a partir de uma ampla revisão teórica do estado da arte do conhecimento na área e a visão de especialistas de diferentes áreas do conhecimento, que enriqueceram a pesquisa, e assim, conseguiu-se chegar a uma clara definição do sacrifício no âmbito do comportamento do consumidor e um modelo de consumo com foco no sacrifício realizado pelo consumidor.

\section{Considerações Finais}

Este artigo objetivou desenvolver uma compreensão holística para o sacrifício a partir das diferentes percepções deste construto em distintas áreas de conhecimento, com vistas a adotar um conceito de sacrifício no consumo com características amplas. A partir da Análise de Conteúdo, foi possível chegar a duas categorias finais do sacrifício descritas como 1) Benefício emocional e/ou material e 2) Perda material e/ou emocional. Tais elementos encontraram suporte na literatura e viabilizou a construção de inferências e interpretações acerca do sacrifício para o consumo.

Foi possível supor que toda prática sacrificial envolve aspectos positivos e negativos e que tais elementos são pesados pelo consumidor na decisão por realizar ou não o sacrifício. Assim, a visão Kenótica não se apresenta nas práticas de consumo, pois há espera de retorno pelo sacrifício. É provável que a atitude para sacrificar esteja ligada ao maior benefício que se possa obter, seja ele um privilégio material ou emocional. Ou seja, tal elemento representa uma característica de troca que seja compensatória na percepção do consumidor.

Em termos acadêmicos, o trabalho contribui para a expansão da percepção do sacrifício no Marketing e Comportamento do Consumidor, observando os itens sacrificiais de outras ciências, refletindo sobre tais abordagens e, principalmente, adaptando estes elementos ao Comportamento do Consumidor. Assim, vem a contribuir com o entendimento de uma prática rotineira da sociedade contemporânea. Ademais, ao tratar do sacrifício como construto base de pesquisa, o artigo auxilia no incentivo de demais estudos que busquem lidar diretamente com esta temática nas perspectivas e espaços de consumo.

Os resultados desta pesquisa também produzem implicações práticas para o mercado, reconhecendo a realização 
do sacrifício por parte de clientes, buscando facilitar o progresso de estratégias de Marketing voltadas a reduzir os possíveis efeitos negativos percebidos no ato de se sacrificar e desenvolver mais benefícios percebidos com a compra desejada.

Embora o presente estudo contemple distintas perspectivas do sacrifício, nas diversas áreas do conhecimento em que o mesmo é estudado, no desenvolvimento do presente trabalho considerou-se, que no processo de compra, o ato de sacrifício é gerado por um processo cognitivo. Apesar de acreditarmos que no processo de compra o aspecto racional desempenha um papel preponderante, entendemos que existem elementos emocionais que atuam como componente motivacional para o ato sacrifício. Nesse sentido, sugere-se que novos estudos sejam desenvolvidos, no sentido de ampliar o modelo proposto, incorporando os aspectos emocionais do ato de sacrifício.

\section{Referências}

AXINN, S. Sacrifice and Value: a Kantian interpretation. Plymouth: Lexington Books, 2010.

BAHR, H. M.; BAHR, K. S. Families and Self-Sacrifice: Alternative Models and Meanings for Family Theory. Social Forces, v. 79, n. 4, p. 1231-1258, 2001.

BARDIN, L. Análise de Conteúdo. Tradução Luís Antero Reto; Augusto Pinheiro. São Paulo: Edições 70, 2011.

BATAILLE, G. The Accursed Share: an essay on general economy. New York: Zone Books, 1988. v. I

BELK, R. W. The Perfect Gift. In: OTNES, C.; BELTRAMINI, R. F. (Eds.). Gift Giving: A Research Anthology. Bowling Green: Bowling Green State University Popular Press, 1996. p. 238.

BELK, R. W.; COON, G. S. Gift Giving as Agapic Love: An Alternative to the Exchange Paradigm Based on Dating Experiences. Journal of Consumer Research, v. 20, n. 3, p. 393-417, 1993.

BELK, R. W.; GER, G.; ASKEGAARD, S. The Fire of Desire: A Multisited Inquiry into Consumer Passion. Journal of Consumer Research, v. 30, n. 3, p. 326-351, 2003.

BELK, R. W.; WALLENDORF, M.; SHERRY, JR., J. F. The Sacred and the Profane in Consumer Behavior: Theodicy on the Odyssey. Journal of Consumer Research, v. 16, n. 1, p. 1-38, 1989.

BOLTON, L. E.; WARLOP, L.; ALBA, J. W. Consumer Perceptions of Price (Un)Fairness. Journal of Consumer Research, v. 29, n. March, p. 474-491, 2003.

BRADFORD, T. W. Intergenerationally Gifted Asset Dispositions. Journal of Consumer Research, v. 36, n. 1, p. 93-111, 2009.

BUBBIO, P. D. Kant's sacrificial turns. International Journal for Philosophy of Religion, v. 73, n. 2, p. 97-115, 2013.

DENZIN, N. K.; LINCOLN, Y. S. The SAGE Handbook of Qualitative Research. Third ed. London: Sage Publications, 2005.

EISENHARDT, K. M. Building Theories from Case Study Research. Academy of Management Review, v. 14, n. 4, p. 532-550, 1989.

EVANS-PRITCHARD, E. E. Nuer religion. Oxford: Clarendon Press, 1956.

FIRTH, R. Offering and Sacrifice: Problems of Organization. The Journal of the Royal Anthropological Institute of Great Britain and Ireland, v. 93, n. 1, p. 12-24, 1963.

FLICK, U. Designing Qualitative Research. London: SAGE Publications, 2008.

FRAZER, J. G. The Golden Bough - A Study in Comparative Religion. New York: MacMillan and Co., 1894. v. 1

FREUD, S. Totem e tabu e outros trabalhos (1913/1914). Tradução Órizon Carneiro Muniz. Rio de Janeiro: Imago, 1996. v. XIII

GIRARD, R. Violence and the Sacred. London: Athlone, 1995.

HALBERTAL, M. On Sacrifice. Princeton: Princeton University Press, 2012.

HUBERT, H.; MAUSS, M. Essai sur la nature et la fonction du sacrifice. L'Année sociologique (1896/18971924/1925), v. 2, p. 29-138, 1897.

IMPETT, E. A.; GORDON, A. M. For the Good of Others: Toward a Positive Psychology of Sacrifice. In: LOPEZ, S. J. (Ed.). Positive psychology: Exploring the best in people. Westport: Praeger, 2008. p. 79-100. 
JAMES, E. O. Origins of Sacrifice. London: John Murray, 1933.

KEENAN, D. K. The Question of Sacrifice. Bloomington: Indiana University Press, 2005.

KRIPPENDORFF, K. Content Analysis: An Introduction to Its Methodology. 2. ed. Thousand Oaks: SAGE Publications, 2012.

LACAN, J. O Seminário, livro 10: a angústia. Tradução Vera Ribeiro. Rio de Janeiro: Jorge Zahar, 2005.

LAPIERRE, J. Customer-perceived value in industrial contexts. Journal of Business \& Industrial Marketing, v. 15, n. 2, p. 122-145, 2000.

LIAO, K.-H.; CHEN, S.-H.; JHOU, Y.-S. The Effect of Price, Quality, Sacrifice, Risks and Value on General Consumers' Perceptions with Aesthetic Medicine. International Academic Conference on Social Sciences, p. $163-171,2014$.

LOUREIRO, S. M. C. Consumer's Love and Willingness to Sacrifice for a Brand. Anzmac, p. 1-9, 2011.

MATEAR, M. A. The Role and Nature of Willingness to Sacrifice in Marketing Relationships. Kingston: Queen's University, 2014.

MATEUS, S. A Identidade como Sacrifício. VI Congresso Português de Sociologia, v. 70, p. 221-235, 2008.

MILLER, D. A Theory of Shopping. Cambridge: Polity Press, 1998.

MONROE, K. B. Pricing: Making Profitable Decisions. New York: McGraw-Hill, 1991.

MONROE, K. B.; KRISHNAN, R. The effect of price on subjective product evaluations. In: JACOBY, J.; OLSON, J. C. (Eds.). Perceived quality: how consumers view stores and merchandise. Lexington: Lexington Books, 1985. p. 209-232.

NEUENDORF, K. A. Content Analysis Guidebook. Thousand Oaks: SAGE Publications, 2002.

OWEN, J.; FINCHAM, F. D.; POLSER, G. Couple Identity, Sacrifice, and Availability of Alternative Partners: Dedication in Friends with Benefits Relationships. Archives of Sexual Behavior, p. 1-7, 2016.

POORTHUIS, M.; SCHWARTZ, J.; TURNER, Y. Review article work on sacrifice. Journal of the Royal Anthropological Institute, v. 22, n. 2, p. 412-414, 2016.

RAMP, W. Transcendence, Liminality and Excess: Durkheim and Bataille on the Margins of 'Sociologie Religieuse'. Journal of Classical Sociology, v. 8, n. 2, p. 208-232, 2008.

RAVALD, A.; GRÖNROOS, C. The value concept and relationship marketing. European Journal of Marketing, v. 30, n. 2, p. 19-30, 1996.

SHERRY JR., J. F. Gift Giving in Anthropological Perspective. Journal of Consumer Research, v. 10, n. 2, p. $157,1983$.

SHILLING, C. "Making things sacred": Re-theorizing the nature and function of sacrifice in modernity. Journal of Classical Sociology, v. 13, n. 3, p. 319-337, 2013.

SHIPTON, P. Trusting and Transcending. Current Anthropology, v. 55, n. S9, p. S51-S61, 2014.

SILVA, A. H. Rituais Corporativos como Estratégia de Legitimação dos Valores Organizacionais em Empresas Familiares. 2012: 145 f. Dissertação (Mestrado em Administração) - Universidade Federal de Santa Maria (UFSC), Santa Maria - RS, 2012.

SIMMEL, G. The Philosophy of Money. 3. ed. London: Routledge, 2004.

SYKERS, A. A. An Essay on the Nature, Design, and Origin, of Sacrifices. London: J. and P. Knapton, 1748.

TYLOR, E. B. Primitive Culture: Researches Into the Development of Mythology, Philosophy, Religion, Art, and Custom. London: John Murray, 1871a. v. 2

Primitive Culture: Researches Into the Development of Mythology, Philosophy, Religion, Art, and Custom. London: John Murray, 1871b. v. 1

WATTS, J. The Rhetoric of Sacrifice Resources for Biblical Study. In: EBERHART, C. A. (Ed.). Ritual and Metaphor: Sacrifice in the Bible. Atlanta: Society of Biblical Literature, 2011. 